\title{
Unbalanced Estrogen Metabolism in Ovarian Cancer
}

\author{
Muhammad Zahid ${ }^{1,{ }^{*}}$, Cheryl L. Beseler ${ }^{2}$, James B. Hall ${ }^{3}$, Tricia LeVan ${ }^{4}$, Ercole L. \\ Cavalieri $^{1,5}$, and Eleanor G. Rogan $1,5,{ }^{*}$ \\ ${ }^{1}$ Department of Environmental, Agricultural and Occupational Health, College of Public Health, \\ University of Nebraska Medical Center, Omaha, NE 68198-4388
}

${ }^{2}$ Department of Psychology, Colorado State University, Fort Collins, CO 80523-1879

${ }^{3}$ Department of Ob-Gyn, Division of Gyn Oncology, Levine Cancer Institute, Carolinas Medical Center, Charlotte, NC 28204

${ }^{4}$ Departments of Internal Medicine and Epidemiology, University of Nebraska Medical Center, Omaha, NE 68198-3332 and VA Nebraska-Western lowa Health Care System Research Service, Department of Veterans Affairs Medical Center, 4101 Woolworth Avenue, Omaha, NE 68105

${ }^{5}$ Eppley Institute for Research in Cancer and Allied Diseases, University of Nebraska Medical Center, Omaha, NE 68198-6805

\section{Abstract}

Greater exposure to estrogens is a risk factor for ovarian cancer. To investigate the role of estrogens in ovarian cancer, a spot urine sample and a saliva sample were obtained from 33 women with ovarian cancer and 34 age-matched controls. Thirty-eight estrogen metabolites, conjugates and DNA adducts were analyzed in the urine samples by using ultraperformance liquid chromatography/tandem mass spectrometry, and the ratio of adducts to metabolites and conjugates was calculated for each sample. The ratio of depurinating estrogen-DNA adducts to estrogen metabolites and conjugates was significantly higher in cases compared to controls $(p<0.0001)$, demonstrating high specificity and sensitivity. DNA was purified from the saliva samples and analyzed for genetic polymorphisms in the genes for two estrogen-metabolizing enzymes. Women with two low-activity alleles of catechol- $O$-methyltransferase plus one or two high-activity alleles of cytochrome P450 1B1 had higher levels of estrogen-DNA adducts and were more likely to have ovarian cancer. These findings indicate that estrogen metabolism is unbalanced in ovarian cancer and suggest that formation of estrogen-DNA adducts plays a critical role in the initiation of ovarian cancer.

\section{Keywords}

ovarian cancer; estrogen-DNA adducts; unbalanced estrogen metabolism; SNPs; catechol-Omethyltransferase; CYP1B1

\section{Introduction}

Ovarian cancer is the fifth leading type of cancer in women in the U.S. [1,2], but first in gynecological cancer mortality [2]. Over seventy percent of ovarian cancers are stage III at

\footnotetext{
*Corresponding authors, E. Rogan, Department of Environmental, Agricultural and Occupational Health, University of Nebraska Medical Center, 984388 Nebraska Medical Center, Omaha, NE 68198-4388, phone 402-559-4095, fax 402-559-7259,

egrogan@unmc.edu, M. Zahid, Department of Environmental, Agricultural and Occupational Health, University of Nebraska Medical Center, 986805 Nebraska Medical Center, Omaha, NE 68198-6805, phone 402-559-8912, fax 402-559-8068, mzahid@unmc.edu.
} 
time of diagnosis, which is causal in the high mortality of these cancers. While our understanding of the molecular make-up of these tumors has progressed, the predominant sub-type remains high-grade serous ovarian cancer, which because of its inherent heterologous construct continues to be problematic to treat. Given the late stage of diagnosis, our inability to diagnose ovarian cancer at an early stage remains the major problem. A panoply of paradigms have been tried to identify these tumors at early stage, but all have been found inadequate. Based on prior data, we hypothesize that ovarian cancer is initiated by imbalanced estrogen metabolism leading to estrogen-DNA adducts that generate mutations in critical genes in the ovarian epithelial cell (Fig. 1) [3]. If so, analysis of estrogen-DNA adducts could provide a tool for early diagnosis [3].

We have previously published data showing increased levels of estrogen-DNA adducts in patients with breast cancer, thyroid cancer, prostate cancer, and non-Hodgkin lymphoma [410]. Because of the association between ovarian cancer and estrogens, we sought to evaluate whether the ratio of estrogen-DNA adducts to estrogen metabolites and conjugates is elevated in women diagnosed with ovarian cancer compared to women without ovarian cancer.

Estrogen metabolism is strongly implicated in the development of ovarian and other hormonal cancers. Many ovarian cancer risk factors are related to exposure to estrogens. Factors that may increase the risk include a positive family history of ovarian cancer, obesity, diet high in saturated fat and meat, cigarette smoking, being menopausal, using hormone replacement therapy and environmental exposures [11,12]. Parity and the use of oral contraceptives are protective against developing ovarian cancer, as is a diet high in olive oil, fish, legumes, beans and vegetables [11,12]. A positive family history is the strongest predictor of ovarian cancer, making assessment of genetic risk factors a fruitful area of prevention research [11]. Genetic studies have targeted single-nucleotide polymorphisms (SNPs) involved in estrogen metabolism and cancer risk. Significant associations have been identified, but effect sizes are modest and results have been inconsistent.

Cytochrome P450 (CYP)1B1 is an initial activating enzyme in the catechol estrogen metabolism pathway (Fig 1). Strong linkage disequilibrium (LD) has been shown in the known variants of CYP1B1 [13], allowing a single SNP to be used as a tag SNP in the gene. The initial formation of 4-hydroxyestrone(estradiol) $\left[4-\mathrm{OHE}_{1}\left(\mathrm{E}_{2}\right)\right]$ is of primary importance in the estrogen metabolism pathway. CYP1B1 catalyzes the 4-hydroxylation of $\mathrm{E}_{1}$ and $\mathrm{E}_{2}$ and was found at higher levels in breast tissue from breast cancer cases than controls [14]. Kinetic experiments demonstrated that five CYP1B1 variants had greater than 2-fold higher activity than the wild-type enzyme and could change the hydroxylation activity of the enzyme, thereby increasing the risk for hormonal cancers [15]. Immunohistochemistry of tissue from 172 primary and metastatic ovarian cancers showed that CYP1B1 was overexpressed in $92 \%$ of the ovarian cancers, but was absent from the 49 normal ovarian tissues from some of these same women [16]. The high level of expression was similar regardless of cancer stage or subtype [16]. In a subset of 20 individuals, the ratio of $4-\mathrm{OHE}_{1}$ to $2-\mathrm{OHE}_{1}$ was lower in those carrying leucine at codon 432 in CYP1B1, demonstrating that the CYP1B1 missense polymorphism modifies estrogen metabolism and that the effects were robust enough to be seen in a small sample size [17]. The few studies of CYP1B1 SNPs in ovarian cancer provide evidence of an association when examined with other polymorphisms such as catechol- $O$-methyltransferase (COMT) [18-20]. Studies of CYP1B1 and breast cancer have examined several CYP1B1 SNPs in a haplotype analysis with few significant associations, but studies of these same polymorphisms in ovarian cancer have assessed a combination of polymorphic genes with more convincing results. Therefore, a polygenic approach is more likely to produce a better understanding of the role of metabolic genes on the formation of DNA adducts and risk of ovarian cancer. 
Downstream of this initial step is COMT, which catalyzes formation of non-reactive methoxy estrogens that cannot be further oxidized. Approximately $25 \%$ of Caucasians are homozygous for a valine to methionine mutation, resulting in 4- to 5-fold lower activity [21]. As noted above, COMT has been associated with ovarian cancer when combined with other polymorphisms in the catechol estrogen pathway [18-20].

DNA adducts resulting from unbalanced estrogen metabolism may represent a modifiable risk factor for ovarian cancer. Because adducts are the result of a series of chemical reactions in the context of a biochemical pathway, analyses of genes that code for the enzymes in the pathway need to be considered as a whole when assessing genetic risk. To date, no study has examined the consequences of having a combination of at-risk variants of these genetic polymorphisms in relation to levels of estrogen metabolites, estrogen conjugates and depurinating estrogen-DNA adducts. In this study we tested the hypotheses that women with ovarian cancer: (1) have a significantly higher ratio of estrogen-DNA adducts relative to estrogen metabolites and conjugates than women without ovarian cancer and (2) are more likely to carry a combination of the high activity CYP1B1 allele and the low activity COMT allele than women without ovarian cancer. We further hypothesized that the ratio of depurinating estrogen-DNA adducts relative to estrogen metabolites and conjugates would be significantly higher in women with the variant alleles for CYP1B1 and COMT compared to women with the non-deleterious alleles.

\section{Methods}

The study protocol was approved by the Institutional Review Boards at Carolinas Medical Center and the University of Nebraska Medical Center (UNMC).

\section{Study Population}

Patients were screened as candidates for the study at the Levine Cancer Institute Gyn Oncology clinic. Post-operatively, those patients who had the appropriate histology based on their surgical findings had the protocol presented to them. The patients were then consented per IRB protocol and the urine and saliva samples were collected at that time, which was within two weeks of surgery and prior to introduction of any chemotherapy. Per protocol, at least $50 \mathrm{ml}$ of urine was collected and, if patients had eaten, we waited 30 minutes to collect the saliva sample. In the group with ovarian cancer, 2 were stage I patients, 2 were stage II, and 30 were stage III/IV.

Based on our study population, normal controls of age-matched volunteers were then identified, consented and the samples collected, as outlined above. The data were gathered by in-person questionnaire at the time the samples were collected. Per protocol, none of the normal controls had a history of any form of cancer, with the exception of basal or squamous cell carcinoma of the skin. Importantly, inclusion criteria prohibited use of exogenous hormones within the three months prior to collecting a urine sample.

\section{Materials}

The estrogen metabolites $2-\mathrm{OHE}_{1}\left(\mathrm{E}_{2}\right)$ and $4-\mathrm{OHE}_{1}\left(\mathrm{E}_{2}\right)$ were synthesized as previously described (22). Quinone conjugates were synthesized by using the procedure of Cao, et al. (23). Estrogen-DNA adducts were synthesized by following reported methods (24-26). All other analytical standards were purchased from Steraloids Inc. (Newport, RI). Phenyl solid phase extraction (SPE) cartridges were purchased from Varian (Palo Alto, CA), and 5000 m.w. cutoff filters were purchased from Millipore (Bedford, MA). All other chemicals and solvents were the highest analytical grade available and purchased from Sigma-Aldrich (St. Louis, MO). 


\section{Sample collection-estrogen compounds}

Approximately $50 \mathrm{ml}$ of urine was obtained in a urine specimen cup containing $1 \mathrm{mg} / \mathrm{ml}$ ascorbic acid (to prevent oxidation of catechol estrogen metabolites). Urine samples were aliquoted, frozen and transferred to the Cavalieri-Rogan laboratory, UNMC, on dry ice and stored at $-80{ }^{\circ} \mathrm{C}$ until analysis. Thus, each analytical sample was thawed only once prior to analysis. A saliva sample $(\sim 2 \mathrm{ml})$ was collected from each subject in an Oragene collection tube. The collection tubes were transferred to the Cavalieri-Rogan laboratory and stored at 3 ${ }^{\circ} \mathrm{C}$ until purification of DNA. The urine and saliva samples from cases and control subjects were collected, handled and stored in the same way.

\section{Analysis of estrogen compounds}

To minimize variation, storage $\left(-80^{\circ} \mathrm{C}\right)$ and transport (on dry ice) of all urine samples were standardized. The samples were randomly divided into sets of 20 each and processed identically. All of the study samples were analyzed in triplicate in a blinded fashion.

A 2-ml aliquot of each urine sample was partially purified by using the SPE phenyl cartridges. The SPE cartridges were pre-conditioned with methanol and the loading buffer, $10 \mathrm{mM}$ ammonium formate, $\mathrm{pH}$ 7. Before loading onto the SPE cartridge, the $\mathrm{pH}$ of each urine sample was adjusted to 7 using $\mathrm{HCl}$ or $\mathrm{NaOH}$, depending upon the initial condition. The cartridges were washed with $250 \mu \mathrm{l}$ of loading buffer, and then the compounds of interest were eluted from the cartridge by using an elution buffer, methanol/10 $\mathrm{mM}$ ammonium formate, $\mathrm{pH} 7$ (90:10) with 1\% acetic acid. The collected eluates were concentrated with a SpeedVac and lyophilized. The lyophilized eluates were reconstituted in $50 \mu \mathrm{l}$ of methanol-water solution (1:1) and passed through a $5000 \mathrm{~m}$.w. cut-off filter. Then $10 \mu \mathrm{l}$ of each sample was subjected to ultraperformance liquid chromatography/tandem mass spectrometry (UPLC-MS/MS) analysis [4].

UPLC-MS/MS analyses were carried out with a Waters Acquity UPLC system connected with a high performance Quattro Micro triple quadrupole mass spectrometer. Analytical separation was carried out by injecting $10 \mu \mathrm{l}$ of each partially purified urine sample into an Acquity UPLC BEH C18 $1.7 \mu \mathrm{m}$ column $(1 \times 100 \mathrm{~mm})$ at a flow rate of $0.15 \mathrm{ml} / \mathrm{min}$. The gradient started with $80 \%$ A $\left(0.1 \%\right.$ formic acid in $\left.\mathrm{H}_{2} \mathrm{O}\right)$ and $20 \% \mathrm{~B}(0.1 \%$ formic acid in $\mathrm{CH}_{3} \mathrm{CN}$ ), changed to $79 \% \mathrm{~A}$ over $4 \mathrm{~min}$, followed by a 6-min linear gradient to $45 \% \mathrm{~A}$, resulting in a total separation time of $10 \mathrm{~min}$. The elutions from the UPLC column were introduced to the Quattro Micro mass spectrometer.

The electrospray ionization (ESI) method was used in positive ion mode with a capillary voltage of $3.0 \mathrm{kV}$, an extractor cone voltage of $3 \mathrm{~V}$, and a detector voltage of $650 \mathrm{~V}$. Desolvation gas flow was maintained at $600 \mathrm{l} / \mathrm{h}$. Cone gas flow was set at $60 \mathrm{l} / \mathrm{h}$. Desolvation temperature and source temperature were set to $200{ }^{\circ} \mathrm{C}$ and $100{ }^{\circ} \mathrm{C}$, respectively. Tandem mass spectrometry (MS/MS) was performed in a multiple reaction monitoring (MRM) mode to produce structural information about a compound by fragmenting specific parent ions inside the mass spectrometer and identifying the resulting fragment ions. Resulting data were processed by using QuanLynx software (Waters) to quantify the estrogen metabolites, conjugates and DNA adducts. Quantification of the estrogen compounds was provided by comparison to standard response curves for each compound. The precision of these analyses is provided by the limit of detection and coefficient of variation for the UPLC-MS/MS method, which were presented earlier (4).

A batch of 20 samples was run in triplicate for UPLC-MS/MS analysis. For each batch of samples, pure standards were used to optimize the UPLC-MS/MS conditions prior to analysis. Also for each batch, the standard mixture was run before the first sample, after the 10th sample and after the last $\left(20^{\text {th }}\right)$ sample to prevent errors due to matrix effect and day-to- 
day instrument variations. In addition, immediately after the initial standard and before the first sample, one set of spiked samples was run to adjust for any drift in the retention time of all estrogen-related compounds due to the matrix effect. After UPLC analysis, the mean value was calculated for all the compounds detected in each sample.

The ratio of adducts to their respective metabolites and conjugates was calculated according to the following formula (4):

$$
\begin{aligned}
\text { ratio } & =\frac{4-\mathrm{OHE}_{1}\left(\mathrm{E}_{2}\right)-1-\mathrm{N} 3 \mathrm{Ade}+4-\mathrm{OHE}_{1}\left(\mathrm{E}_{2}\right)-1-\mathrm{N} 7 \mathrm{Gua}}{4-\text { catecholestrogens }+4-\text { catecholestrogen conjugates }} \\
& +\frac{2-\mathrm{OHE}_{1}\left(\mathrm{E}_{2}\right)-6-\mathrm{N} 3 \mathrm{Ade}}{2-\text { catecholestrogens }+2-\text { catecholestrogen conjugates }} \times 1000
\end{aligned}
$$

The estrogen metabolites include 2- $\mathrm{OHE}_{1}\left(\mathrm{E}_{2}\right)$ and 4-OHE $\mathrm{E}_{1}\left(\mathrm{E}_{2}\right)$. The conjugates include 2$\mathrm{OCH}_{3} \mathrm{E}_{1}\left(\mathrm{E}_{2}\right), 4-\mathrm{OCH}_{3} \mathrm{E}_{1}\left(\mathrm{E}_{2}\right), 2-\mathrm{OHE}_{1}\left(\mathrm{E}_{2}\right)-1$-glutathione (SG), 2-OHE $\left(\mathrm{E}_{2}\right)-4-\mathrm{SG}, 2-$ $\mathrm{OHE}_{1}\left(\mathrm{E}_{2}\right)-1$-cysteine $(\mathrm{Cys}), 2-\mathrm{OHE}_{1}\left(\mathrm{E}_{2}\right)-4-\mathrm{Cys}, 2-\mathrm{OHE}_{1}\left(\mathrm{E}_{2}\right)-1-\mathrm{N}$-acetylcysteine (NAcCys), 2-OHE ${ }_{1}\left(\mathrm{E}_{2}\right)-4-\mathrm{NAcCys}, 4-\mathrm{OHE}_{1}\left(\mathrm{E}_{2}\right)-2-\mathrm{SG}$, 4-OHE $\mathrm{OH}_{1}\left(\mathrm{E}_{2}\right)-2-\mathrm{Cys}$, and 4-OHE $\mathrm{O}_{1}\left(\mathrm{E}_{2}\right)-2-$ NAcCys. The adducts include 4-OHE ${ }_{1}\left(\mathrm{E}_{2}\right)-1-\mathrm{N} 3 \mathrm{Ade}, 4-\mathrm{OHE}_{1}\left(\mathrm{E}_{2}\right)-1-\mathrm{N} 7 \mathrm{Gua}$, and 2$\mathrm{OHE}_{1}\left(\mathrm{E}_{2}\right)-6-\mathrm{N} 3 \mathrm{Ade}$.

The concentration of each of the compounds and the ratio of depurinating N3Ade and N7Gua adducts to the sum of their respective estrogen metabolites and conjugates in each urine sample provides a ratio, which reflects the degree of imbalance in estrogen metabolism that may lead to cancer initiation.

\section{Sample Collection-SNPs}

Saliva samples were used to obtain DNA. Self-collection, stabilization, transportation, storage and purification was accomplished using the Oragene Method [27]. Oragene is a non-invasive, user-friendly collection method that produces high quality DNA from approximately $2 \mathrm{ml}$ of saliva. DNA samples were genotyped using matrix-assisted laser desorption/ionization time-of-flight mass spectrometry (Sequenom Inc., San Diego, CA, USA). Multiplex polymerase chain reaction assays and associated extension reactions were designed using SpectroDesigner software (Sequenom). Primer extension reactions were analyzed with a MassArray mass spectrometer (Bruker Daltonik GmbH, Bremen, Germany). For genotyping quality control, Hardy-Weinberg calculations were performed to ensure that each marker was within the expected allelic population equilibrium. The genes of interest were those that code for CYP1B1 (V432L; SNP rs1056836) and COMT (V158M; SNP rs4680).

\section{Analysis of SNPs}

One saliva sample did not produce a CYP1B1 genotype and another did not produce a COMT genotype, although the genotyping was successful for the other SNP. These two samples were excluded from the combined analysis. Women with at least one CYP1B1 high activity $\mathrm{G}$ allele combined with two low activity $\mathrm{A}$ alleles in COMT were hypothesized to have the highest DNA adduct ratio and, thus, the highest risk of ovarian cancer. Because we did not know the impact of having one or two variant alleles, the CYP1B1 genotypes were coded in three categories $(\mathrm{CC}=0, \mathrm{CG}=1, \mathrm{GG}=2)$ and two categories $(\mathrm{CC}=0, \mathrm{CG} / \mathrm{GG}=1)$. Similarly for COMT, the genotypes were coded in three categories $(\mathrm{GG}=0, \mathrm{GA}=1, \mathrm{AA}=2)$ and collapsed into two $(\mathrm{GG}=0, \mathrm{GA} / \mathrm{AA}=1)$. Allele and genotype frequencies were tested for Hardy-Weinberg Equilibrium (HWE) in controls, and in cases and controls combined due to the small sample size. 


\section{Independent variables}

The primary exposures of interest were the DNA adduct ratio, modeled as a continuous variable, and the at-risk genotypes for CYP1B1 and COMT. Applying a natural log transformation to the DNA adduct ratio resulted in a normally-distributed variable by the Shapiro-Wilk test $(\mathrm{p}=0.21)$. Demographic information collected included race (white $=0$, African-American=1), education ( Shigh school $=0$, >high school=1) and marital status (married=0, unmarried=1). Continuous covariates included age of menarche, age at first and last baby, age at last menstrual period, years of oral contraceptive use, body mass index (BMI) and years of cigarette smoking. Binary covariates were coded to model an increased risk for ovarian cancer; a value of 1 reflects greater risk based on previous studies and 0 the reference group. The binary variables included first degree relative with cancer (yes=1), first degree relative with ovarian cancer (yes $=1$ ), oral contraceptive use $($ no $=1)$, post-menopausal (yes $=1$ ), ever smoked cigarettes (yes=1), history of HRT use (yes=1), parity (no children=1) and current alcohol use (yes=1). Additional covariates included frequency and intensity of physical activity $(>2$ days/week, strenuous $=0 ; \underline{2}$ days/week, light/moderate=1).

\section{Dependent variable}

The outcome was a diagnosed ovarian cancer. The outcome was not restricted to a specific ovarian cancer subtype. All cases were newly diagnosed and had not yet undergone treatment at the time of recruitment into the study and sample collection.

\section{Statistical Analyses}

\section{Bivariate analyses}

Due to small numbers in many of the cells, the categorical variables were dichotomized as described above. The chi-square and Fisher's exact test were used to assess differences in cases and controls on potentially confounding characteristics. Mean differences in continuous variables were compared between cases and controls using the t-test for normally-distributed variables (age, age at last baby, BMI, years of smoking, adduct ratio) and the non-parametric Wilcoxon two-sample test when non-normality was present (age at menarche, age at first baby, years of oral contraceptive use, age at last menstrual period).

Significant tests for mean differences in the DNA adduct ratio by CYP1B1 and COMT genotypes were compared using analysis of variance for the three-category genotype and the t-test for the two-category genotype. We also tested whether having one or two high activity CYP1B1 alleles together with two low activity COMT alleles was associated with having a high DNA adduct ratio using a t-test and logistic regression models. We tested whether any of the covariates were associated with both the DNA adduct ratio and ovarian cancer to assess potential confounding.

\section{Receiver operating characteristic curves}

We used logistic regression to generate a Receiver Operating Characteristic (ROC) curve and calculated the area under the receiver operating characteristic curves (AUC) to determine whether the DNA adduct ratio significantly classified women with ovarian cancer compared to what would be predicted by chance. We also plotted sensitivity and specificity to find the cutoff value for the adduct ratio that maximized the sensitivity and specificity. We previously showed that the DNA adduct ratio exhibited a high degree of sensitivity for a given specificity for both breast cancer and thyroid cancer $[6,7]$. 


\section{Mediation analysis}

We tested for mediation by the adduct ratio on the association between having at least one high activity CYP1B1 allele combined with having two low activity COMT alleles and ovarian cancer to see whether the DNA adduct ratio may be a mediator on the causal pathway. Two consecutive regressions were used in a path analysis model. In the first regression, the combined at-risk genotype was a predictor of adduct ratio in a linear regression model and in the second, the adduct ratio predicted having ovarian cancer in a logistic regression model.

The path analysis was conducted in MPlus version 6 [28]. All other analyses were conducted in SAS version 9.3 (The SAS Institute, Cary, NC). Results were considered significant at the $\mathrm{p}=0.05$ level of confidence; $95 \%$ confidence intervals are reported.

\section{Results}

\section{Sample characteristics}

The 67 women with questionnaire data and a urine and saliva sample were primarily white, married and well-educated (Table 1). Of the 33 cases of ovarian cancer, $22(66.7 \%)$ were the serous subtype; the remaining were clear cell, endometrioid, fallopian and four were undetermined. The cases of ovarian cancer did not differ from the controls by age due to having been age-matched, nor did they differ by age at menarche, body mass index and years having smoked cigarettes (Table 1). As has been reported previously in the literature with similar effect sizes [29], significant differences were observed for age at first birth (Cohen's $\mathrm{D}=0.69$, large effect) and years of oral contraceptive use (Cohen's $\mathrm{D}=0.50$, medium effect). Controls were likely to be older when they gave birth to their last child and tended to be older at the time of their last menstrual period compared to cases. Nearly all the women were post-menopausal, few had ever used HRT and most did not have a family history of ovarian cancer (Table 1). Most of the women reported being in good, very good or excellent health. Indicative of being a healthy sample of women, $66 \%$ of the women in this sample took a daily multivitamin and $75 \%$ took one or more antioxidants.

Cases and controls differed in lifestyle factors such as exercise and alcohol consumption, but these differences were partially explained by educational attainment (Table 1). Only three women were current smokers, but women who reported ever having smoked cigarettes had an elevated risk of ovarian cancer $(\mathrm{OR}=2.59$; $\mathrm{CI}$ 0.95-7.05). Previous studies have been inconsistent in reporting an increased risk of ovarian cancer in women who have a history of cigarette smoking, although smoking has been associated with the mucinous subtype [30].

\section{Estrogen metabolism in cases and controls}

The first outcome of this research was comparison of the ratio of estrogen-DNA adducts to estrogen metabolites and conjugates in urine samples from cases and controls. The ratio, rather than simply the level of adducts, for two reasons. First, the level of estrogen-DNA adducts varies in different people and does not reliably show a difference between cases and controls (see Supplementary Material). Second, the ratio provides a measure of the degree of imbalance in a person's estrogen metabolism; greater imbalance leads to higher levels of reactive catechol estrogen quinones.

The DNA adduct ratio was significantly associated with having ovarian cancer $(\mathrm{p}<0.0001)$ (Table 1, Fig. 2). The mean ratio for cases was $91.4 \pm 43.1$, whereas the mean ratio for controls was $24.7 \pm 12.7$. The results from 10 women with ovarian cancer and 10 healthy control women are presented in Supplementary Material. In adjusted logistic regression models, other significant risk factors became insignificant with the adduct ratio in the model. 
Additionally, the adduct ratio was not significantly associated with any other risk factors for ovarian cancer, suggesting that the results cannot be explained by confounding by other known risk factors.

\section{Genetic polymorphisms in estrogen-metabolizing enzymes}

The second outcome of this project was the analysis of SNPs in the genes for the estrogenmetabolizing enzymes CYP1B1 (V432L) and COMT (V158M). CYP1B1 primarily catalyzes the oxidation of $\mathrm{E}_{1}$ and $\mathrm{E}_{2}$ to $4-\mathrm{OHE}_{1}\left(\mathrm{E}_{2}\right)$. In contrast, COMT is a protective enzyme because COMT catalyzes the methylation of catechol estrogens to methoxyestrogens, which cannot be further oxidized (Fig. 1).

The two genetic polymorphisms studied here were all in Hardy-Weinberg equilibrium (HWE) in controls (CYP1B1 $\chi^{2}=0.12, \mathrm{p}=0.73$; COMT: $\chi^{2}=0.25, \mathrm{p}=0.61$ ). Because the numbers were small, we also tested for HWE in the combined sample of cases and controls and found that all SNPS were in HWE. Not surprisingly, no differences were seen in allele and genotype frequencies in African American women compared to white women, but the number of African American women was small. Table 2A shows the prevalence of alleles and genotypes for each of the two SNPS used in the analyses.

The DNA adduct ratio was increasingly higher in women with one and two high activity CYP1B1 alleles, showing the effect that high activity CYP1B1 alleles have on adduct levels. (Table 2A). No such pattern can be seen for COMT. Individually, neither of the two SNPs showed significant associations with either the DNA adduct ratio or ovarian cancer.

However, in women who were homozygous for the low activity COMT allele, the CYP1B1 high activity allele was associated with a significantly increased DNA adduct ratio (Table 2B). The combination of high-risk CYP1B1 and COMT alleles also elevated the odds of having ovarian cancer, although the confidence intervals are wide and the results do not reach statistical significance (Table $2 \mathrm{~B}$ ). No significant difference was seen in women who were heterozygous for the COMT low activity allele (Met). Previous studies have also reported negative findings for COMT and risk of ovarian cancer when assessed separately from other estrogen-metabolizing genes [18,20,31] .

\section{Receiver operating characteristic curves}

Using a cutoff value of 43 for the adduct ratio, sensitivity is 90.9 and specificity is 91.2 , the point at which the lines intersect in Figure 3. The AUC was 0.98 (CI 0.96-1.00; p<0.0001), making it nearly perfect at classifying women with ovarian cancer with high sensitivity and high specificity (Fig. 3).

\section{Mediation analysis}

The presence of one or more high activity CYP1B1 alleles with two low activity COMT alleles was significantly and positively associated with the adduct ratio $(\mathrm{p}=0.02)$. The linear regression coefficient represents an increase of $0.61(\mathrm{SE}=0.26)$ in the adduct ratio as a woman moves from the low genetic risk category to the higher genetic risk category. The effect size of the association between the DNA adduct ratio and risk of ovarian cancer was much stronger with a log odds of 6.17 (SE=1.67; $\mathrm{p}<0.0001$ ) (Fig. 4). The significant pathways indicate that the DNA adduct ratio acts as a mediator between genetic risk and ovarian cancer. 


\section{Discussion and Conclusions}

In this article, we report the novel finding that the ratio of depurinating estrogen-DNA adducts to estrogen metabolites and conjugates is significantly elevated in women with ovarian cancer, compared to the ratio in age-matched control women (Fig. 2).

We hypothesize that initiation of ovarian cancer, analogously to breast cancer [4-6], thyroid cancer [7], prostate cancer [8,9] and non-Hodgkin lymphoma [10], arises from estrogens acting not as hormones, but as chemicals that are metabolically activated to the ultimate carcinogenic metabolites, estrogen-3,4-quinones (Fig. 1). Reaction of these metabolites with DNA forms estrogen-DNA adducts that can initiate the series of events leading to ovarian cancer. In this mechanism of cancer initiation, estrogen metabolism is unbalanced toward oxidative metabolism. This results in more oxidation by CYP1B1 to $4-\mathrm{OHE}_{1}\left(\mathrm{E}_{2}\right)$ and then to the reactive catechol estrogen-3,4-quinones and less protection by enzymes such as COMT (Fig. 1). The estrogens, $\mathrm{E}_{1}$ and $\mathrm{E}_{2}$, are oxidized by CYP1B1 to the catechol estrogens, 4$\mathrm{OHE}_{1}\left(\mathrm{E}_{2}\right)$ and then to the estrogen 3,4-quinones [ $\left.\mathrm{E}_{1}\left(\mathrm{E}_{2}\right)-3,4-\mathrm{Q}\right]$, which react with DNA to form the 4-OHE $1\left(\mathrm{E}_{2}\right)-1-\mathrm{N} 3 \mathrm{Ade}$ and $4-\mathrm{OHE}_{1}\left(\mathrm{E}_{2}\right)-1-\mathrm{N} 7 \mathrm{Gua}$ adducts [3]. These adducts depurinate from DNA, leaving apurinic sites in the DNA that can generate oncogenic mutations. These mutations start the process that can result in cancer (Fig. 1).

Stable estrogen-DNA adducts comprise a small portion of the total adducts formed by catechol estrogen quinones. In vitro, reaction of catechol estrogen quinones or enzymeactivated catechol estrogens with DNA resulted in at least 99\% depurinating adducts and less than $1 \%$ stable adducts [26]. In the animal models mouse skin and rat mammary gland treated with $\mathrm{E}_{2}-3,4-\mathrm{Q}$, depurinating adducts comprised more than $99 \%$ of the total adducts formed, with less than $1 \%$ stable adducts [32,33]. In addition, the marginally carcinogenic 2 $\mathrm{OHE}_{2}$ [34-36] forms 10-40 times more stable adducts when reacted with DNA in vitro than the carcinogenic 4- $\mathrm{OHE}_{2}$ [37]. These results strongly support a critical role of depurinating estrogen-DNA adducts and a minimal role of stable estrogen-DNA adducts in cancer initiation.

The estrogen-DNA adducts travel through the circulatory system and can be measured in the urine or serum (Fig. 2) [4-10]. This finding is consistent with the hypothesis that formation of depurinating estrogen-DNA adducts, which generate apurinic sites in the DNA, leads to mutations that can initiate the series of events resulting in ovarian cancer [3]. At present, we do not know whether the adducts detected in urine are formed in the ovary, or elsewhere. It is possible that the DNA damage occurs in a variety of organs and cancer further develops in a specific organ because of other influences.

We hypothesized that the DNA adduct ratio may act as an intermediate on the causal pathway between genetic polymorphisms and risk of hormonal cancers. The estrogen quinone resulting from CYP1B1 activity may proceed to adduct formation in the presence of low methylation activity by COMT. A number of studies have examined the effects of combinations of mutant alleles, but have not linked these mutant alleles to the ratio of adducts to metabolites and conjugates. Having both a CYP1B1 Val allele and a COMT Met allele increased the risk of ovarian cancer in a study of 73 cases and 76 controls (OR 2.6, 95\% CI 1.2-5.5) [31]. An increased risk of prostate cancer was observed in a study of 1,983 men $(1,101$ cancer cases and 882 controls) with combined CYP1B1 Val and COMT Met $(\mathrm{OR}=1.38,95 \%$ CI 1.11-1.72) [38]. The DNA adduct ratio is a more proximal outcome than ovarian cancer and represents the initiation step in the cancer pathway, making it an early marker of risk for ovarian cancer, as well as other hormonal cancers.

Several of the strongest associations with ovarian cancer (age at first birth and oral contraceptive use) were replicated in this study of 67 women. Other associations may be due 
to the specific characteristics of this sample, such as higher educational attainment in the controls compared to the cases. The subjects tended to be healthy, took vitamins and supplements, and more than half reported eating vegetables every day, all indicators of a healthy lifestyle. The primary risk factors of interest in this study were the prevalence of specific genotypes and the adduct ratio, neither of which would be expected to be influenced by differences in educational level of the study participants. The finding that genetic polymorphisms in CYP1B1 and COMT predispose women toward ovarian cancer strongly suggests that unbalanced estrogen metabolism leading to greater formation of estrogen-DNA adducts is a critical factor in the initiation of ovarian cancer. This hypothesis is also supported by the observation of significantly higher ratios of estrogen-DNA adducts to estrogen metabolites and conjugates in women at high risk for breast cancer, compared to women at normal risk [4-6]. It is possible that the presence of ovarian cancer resulted in the high estrogen-DNA adduct ratios observed in the women with ovarian cancer; however, the association with genetic polymorphisms in CYP1B1 and COMT cannot be attributed to the presence of cancer. Therefore, it is far more likely that the DNA damage detected as estrogen-DNA adducts is a causal factor in the etiology of ovarian cancer.

In conclusion, estrogen metabolism was unbalanced and the ratio of depurinating estrogenDNA adducts to estrogen metabolites and conjugates was significantly higher in women with ovarian cancer compared to control women not diagnosed with cancer $(\mathrm{p}<0.0001)$. These results suggest that formation of estrogen-DNA adducts plays a critical role in the initiation of ovarian cancer. Furthermore, future studies of the formation of depurinating estrogen-DNA adducts in relation to early detection of ovarian cancer may suggest approaches for prevention.

\section{Supplementary Material}

Refer to Web version on PubMed Central for supplementary material.

\section{Acknowledgments}

We thank the Department of Defense Ovarian Cancer Research Program (grant W81XWH-10-1-0175) for support of this study. Core support at the Eppley Institute was supported by grant P30 36727 from the National Cancer Institute.

\section{Abbreviations}

\begin{tabular}{|c|c|}
\hline AUC & area under the ROC curve \\
\hline COMT & catechol- $O$-methyltransferase \\
\hline CYP & cytochrome P450 \\
\hline Cys & cysteine \\
\hline ESI & electrospray ionization \\
\hline HWE & Hardy-Weinberg equilibrium \\
\hline LD & linkage disequilibrium \\
\hline MRM & multiple reaction monitoring \\
\hline MS/MS & tandem mass spectrometry \\
\hline NAcCys & $N$-acetylcysteine \\
\hline $4-\mathrm{OHE}_{1}\left(\mathrm{E}_{2}\right)$ & 4-hydroxyestrone(estradiol) \\
\hline
\end{tabular}


ROC receiver operating characteristic

SEER

SG

SNPs

SPE

UNMC

UPLC-MS/MS
Surveillance, Epidemiology and End Results

glutathione

single-nucleotide polymorphisms

solid phase extraction

University of Nebraska Medical Center

ultraperformance liquid chromatography/tandem mass spectrometry

\section{Literature Cited}

1. Greenlee RT, Murray T, Bolden S, Wingo PA. Cancer statistics, 2000. CA Cancer J Clin. 2000; 50:7-33. [PubMed: 10735013]

2. Horner, MJ.; Ries, LAG.; Krapcho, M.; Neyman, N.; Aminou, R.; Howlader, N.; Altekruse, SF.; Feuer, EJ.; Huang, L.; Mariotto, A.; Miller, BA.; Lewis, DR., et al., editors. SEER Cancer Statistics Review, 1975-2006. Bethesda, MD: National Cancer Institute; 2009. http://seer.cancer.gov/csr/ 1975_2006/, based on November 2008 SEER data submission, posted to the SEER web site

3. Cavalieri E, Rogan E. Unbalanced metabolism of endogenous estrogens in the etiology and prevention of human cancer. J Steroid Biochem Mol Biol. 2011; 125:169-180. [PubMed: 21397019]

4. Gaikwad NW, Yang L, Muti P, Meza JL, Pruthi S, Ingle JN, Rogan EG, Cavalieri EL. The molecular etiology of breast cancer: Evidence from biomarkers of risk. Int J Cancer. 2008; 122:1949-1957. [PubMed: 18098283]

5. Gaikwad NW, Yang L, Pruthi S, Ingle JN, Sandhu N, Rogan E, Cavalieri E. Urine biomarkers of risk in the molecular etiology of breast cancer. Breast Cancer: Basic \& Clin Res. 2009; 3:1-8.

6. Pruthi S, Yang L, Sandhu NP, Ingle JN, Beseler CL, Suman VJ, Cavalieri EL, Rogan EG. Evaluation of serum estrogen-DNA adducts as potential biomarkers of breast cancer risk. J Steroid Biochem Mol Biol. 2012; 132:73-79. [PubMed: 22386952]

7. Zahid M, Goldner W, Beseler C, Rogan E, Cavalieri E. Unbalanced estrogen metabolism in thyroid cancer. Int J Cancer. 2013 in press.

8. Markushin Y, Gaikwad N, Zhang H, Rogan E, Cavalieri E, Trock B, Pavlovich C, Jankowiak R. Potential biomarker for early risk assessment of prostate cancer. Prostate. 2006; 66:1565-1571. [PubMed: 16894534]

9. Yang L, Gaikwad N, Meza J, Cavalieri E, Muti P, Trock B, Rogan E. Novel biomarkers for risk of prostate cancer. Results from a case-control study. Prostate. 2009; 69:41-48. [PubMed: 18816637]

10. Gaikwad NW, Yang L, Weisenburger DD, Vose J, Beseler C, Rogan EG, Cavalieri EL. Urinary biomarkers suggest that estrogen-DNA adducts may play a role in the aetiology of non-Hodgkin lymphoma. Biomarkers. 2009; 14:502-512. [PubMed: 19863189]

11. Hunn J, Rodriguez GC. Ovarian cancer: Etiology, risk factors, and epidemiology. Clin Obstet Gynecol. 2012; 55:3-23. [PubMed: 22343225]

12. Salehi F, Dunfield L, Phillips KP, Krewski D, Vanderhyden BC. Risk factors for ovarian cancer: An overview with emphasis on hormonal factors. J Toxicol Environ Health B Crit Rev. 2008; 11:301-321. [PubMed: 18368558]

13. Beuten J, Gelfond JAL, Byrne JJ, Balic I, Craandall AC, Johnson-Pais TL, Thompson IM, Price DK, Leach RJ. CYP1B1 variants are associated with prostate cancer in non-Hispanic and Hispanic Caucasians. Carcinogenesis. 2008; 29:1751-1757. [PubMed: 18544568]

14. Singh S, Chakravarti D, Edney JA, Hollins RR, Johnson PJ, West WW, Higginbotham SM, Cavalieri EL, Rogan EG. Relative imbalances in the expression of estrogen-metabolizing enzymes in the breast tissue of women with breast carcinoma. Oncol Rep. 2005; 14:1091-1096. [PubMed: 16142378] 
15. Hanna IH, Dawling S, Roodi N, Guengerich FP, Parl FF. Cytochrome P450 1B1 (CYP1B1) pharmacogenetics: Association of polymorphisms with functional differences in estrogen hydroxylation activity. Cancer Res. 2000; 60:3440-3444. [PubMed: 10910054]

16. McFadyen MCE, Cruickshank ME, Miller ID, McLeod HL, Melvin WT, Haites NE, Parkin D, Murray GI. Cytochrome p450 CYP1B1 over-expression in primary and metastatic ovarian cancer. Br J Cancer. 2001; 85:242-246. [PubMed: 11461084]

17. Paracchini V, Pedotti P, Raimondi S, Garte S, Bradlow HL, Sepkovic DW, Taioli E. A common CYP1B1 polymorphism is associated with $2-\mathrm{OHE}_{1} / 16-\mathrm{OHE}_{1}$ urinary estrone ratio. Clin Chem Lab Med. 2005; 43:702-706. [PubMed: 16207128]

18. Sellers TA, Schildkraut JM, Pankratz VS, Vierkant RA, Fredericksen ZS, Olson JE, Cunningham J, Taylor W, Liebow M, McPherson C, Hartmann LC, Pal T, Adjei AA. Estrogen bioactivation, genetic polymorphisms, and ovarian cancer. Cancer Epidemiol Biomarkers Prev. 2005; 14:25362543. [PubMed: 16284375]

19. Delort L, Chalabi N, Satih S, Rabiau N, Kwiatkowski F, Bignon Y-J, Bernard-Gallon DJ. Association between genetic polymorphisms and ovarian cancer risk. Anticancer Res. 2008; 28:3079-3081. [PubMed: 19031960]

20. Holt SK, Rossing MA, Malone KE, Schwartz SM, Weiss NS, Chen C. Ovarian cancer risk and polymorphisms involved in estrogen catabolism. Cancer Epidemiol Biomarkers Prev. 2007; 16:481-489. [PubMed: 17372243]

21. Dawling S, Roodi N, Mernaugh RL, Wang X, Parl FF. Catechol-O-methyltransferase (COMT)mediated metabolism of catechol estrogens: comparison of wild-type and variant COMT isoforms. Cancer Res. 2001; 61:6716-6722. [PubMed: 11559542]

22. Saeed M, Rogan E, Cavalieri E. Synthesis of the catechols of natural and synthetic estrogens by using 2-iodoxybenzoic acid (IBX) as the oxidizing agent. Steroids. 2005; 70:173-178. [PubMed: 15763595]

23. Cao K, Stack DE, Ramanathan R, Gross ML, Rogan EG, Cavalieri EL. Synthesis and structure elucidation of estrogen quinones conjugated with cysteine, $\mathrm{N}$-acetylcysteine and glutathione. Chem Res Toxicol. 1998; 11:909-916. [PubMed: 9705753]

24. Stack D, Byun J, Gross ML, Rogan EG, Cavalieri E. Molecular characteristics of catechol estrogen quinones in reactions with deoxyribonucleosides. Chem Res Toxicol. 1996; 9:851-859. [PubMed: 8828920]

25. Li K-M, Todorovic R, Devanesan P, Higginbotham S, Köfeler H, Ramanathan R, Gross ML, Rogan EG, Cavalieri EL. Metabolism and DNA binding studies of 4-hydroxyestradiol and estradiol-3,4-quinone in vitro and in female ACI rat mammary gland in vivo. Carcinogenesis. 2004; 25:289-297. [PubMed: 14578156]

26. Zahid M, Kohli E, Saeed M, Rogan E, Cavalieri E. The greater reactivity of estradiol-3,4-quinone versus estradiol-2,3-quinone with DNAin the formation of depurinating adducts Implications for tumor-initiating activity. Chem Res Toxicol. 2006; 19:164-172. [PubMed: 16411670]

27. Rylander-Rudqvist T, Hakansson N, Tybring G, Wolk A. Quality and quantity of saliva DNA obtained from the self-administrated Oragene method - A pilot study on the cohort of Swedish men. Cancer Epidemiol Biomarkers Prev. 2006; 15:1742-1745. [PubMed: 16985039]

28. Muthen, LK.; Muthen, BO. Mplus User's Guide. Los Angeles CA: Muthen \& Muthen; 2010.

29. Moorman PG, Calingaert B, Palmieri RT, Iversen ES, Bentley RC, Halabi S, Berchuck A, Schildkraut JM. Hormonal risk factors for ovarian cancer in premenopausal and postmenopausal women. Am J Epidemiol. 2008; 167:1059-1069. [PubMed: 18303003]

30. Zhang Y, Coogan PF, Palmer JR, Strom BL, Rosenberg L. Cigarette smoking and increased risk of mucinous epithelial ovarian cancer. Am J Epidemiol. 2004; 159:133-139. [PubMed: 14718214]

31. Goodman MT, McDuffie K, Kolonel LN, Terada K, Donlon TA, Wilkens LR, Guo C, Marchand LL. Case-control study of ovarian cancer and polymorphisms in genes involved in catechol estrogen formation and metabolism. Cancer Epidemiol Biomarkers Prev. 2001; 10:209-216. [PubMed: 11303589]

32. Chakravarti D, Mailander P, Li K-M, Higginbotham S, Zhang H, Gross ML, Cavalieri E, Rogan E. Evidence that a burst of DNA depurination in SENCAR mouse skin induces error-prone repair and form mutations in the H-ras gene. Oncogene. 2001; 20:7945-7953. [PubMed: 11753677] 
33. Mailander PC, Meza JL, Higginbotham S, Chakravarti D. Induction of A.T to G.C mutations by erroneous repair of depurinated DNA following estrogen treatment of the mammary gland of ACI rats. J Steroid Biochem Mol Biol. 2006; 101:204-715. [PubMed: 16982187]

34. Liehr JG, Fang WF, Sirbasku DA, Ari-Ulubelen A. Carcinogenicity of catechol estrogens in Syrian hamsters. J Steroid Biochem. 1986; 24:353-356. [PubMed: 3009986]

35. Li JJ, Li SA. Estrogen carcinogenesis in Syrian hamster tissues: Role of metabolism. Fed Proc. 1987; 46:1858-1863. [PubMed: 3030825]

36. Newbold RR, Liehr JG. Induction of uterine adenocarcinoma in CD-1 mice by catechol estrogens. Cancer Res. 2000; 60:235-237. [PubMed: 10667565]

37. Dwivedy I, Devanesan P, Cremonesi P, Rogan E, Cavalieri E. Synthesis and characterization of estrogen 2,3- and 3,4-quinones. Comparison of DNA adducts formed by the quinones versus horseradish peroxidase-activated catechol estrogens. Chem Res Toxicol. 1992; 5:828-833. [PubMed: 1336990]

38. Cussenot O, Azzouzi AR, Nicolaiew N, Fromont G, Mangin P, Cormier L, Fournier G, Valeri A, Larre S, Thibault F, Giordanella JP, Pouchard M, et al. Combination of polymorphisms from genes related to estrogen metabolism and risk of prostate cancers: The hidden face of estrogens. $\mathrm{J}$ Clin Oncol. 2007; 25:3596-3602. [PubMed: 17704407] 


\section{Novelty and Impact Statements}

We demonstrate here unbalanced estrogen metabolism resulting in formation of estrogenDNA adducts in women with ovarian cancer compared to women without ovarian cancer. Second, with two low-activity alleles of catechol- $O$-methyltransferase plus one or two high-activity alleles of cytochrome P450 1B1, women have higher levels of estrogenDNA adducts and are more likely to have ovarian cancer. These results indicate that formation of estrogen-DNA adducts plays a critical role in the etiology of ovarian cancer. 
<smiles>[R]C1CCC2C3CCc4c(ccc(O)c4OC)C3CCC12CC(=O)OC</smiles>

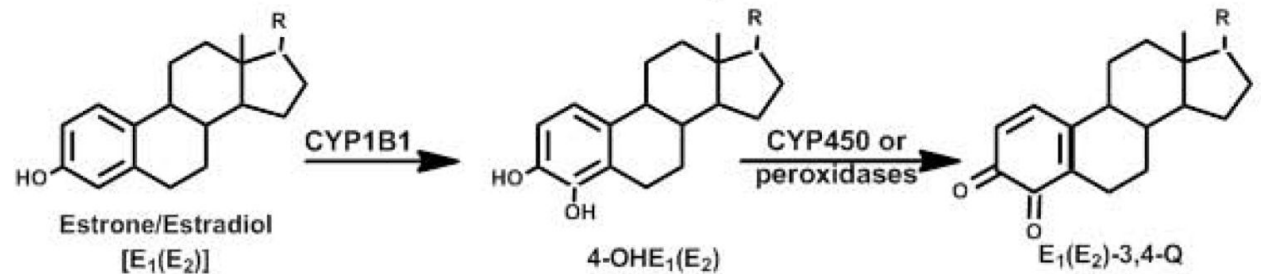

$E_{1}: R,=0$

$E_{2}: R,-O H$<smiles>Cn1cnc2cc(N)[nH]c(=O)c21</smiles><smiles>Cc1cc(O)c(O)c2c1C(C)C(C1CCCC1)CC2</smiles>

4-OHE $1\left(E_{2}\right)-1-N 7 G u a$<smiles>[R]C1CCC2C3CCc4c(O)c(O)cc(-n5cnc(N)c6ncnc5-6)c4C3CCC12C</smiles>

4-OHE $1\left(\mathrm{E}_{2}\right)$-1-N3Ade

Depurinating Adducts

\section{Ovarian cancer

Figure 1.

Proposed metabolic pathway in cancer initiation by estrogens. 


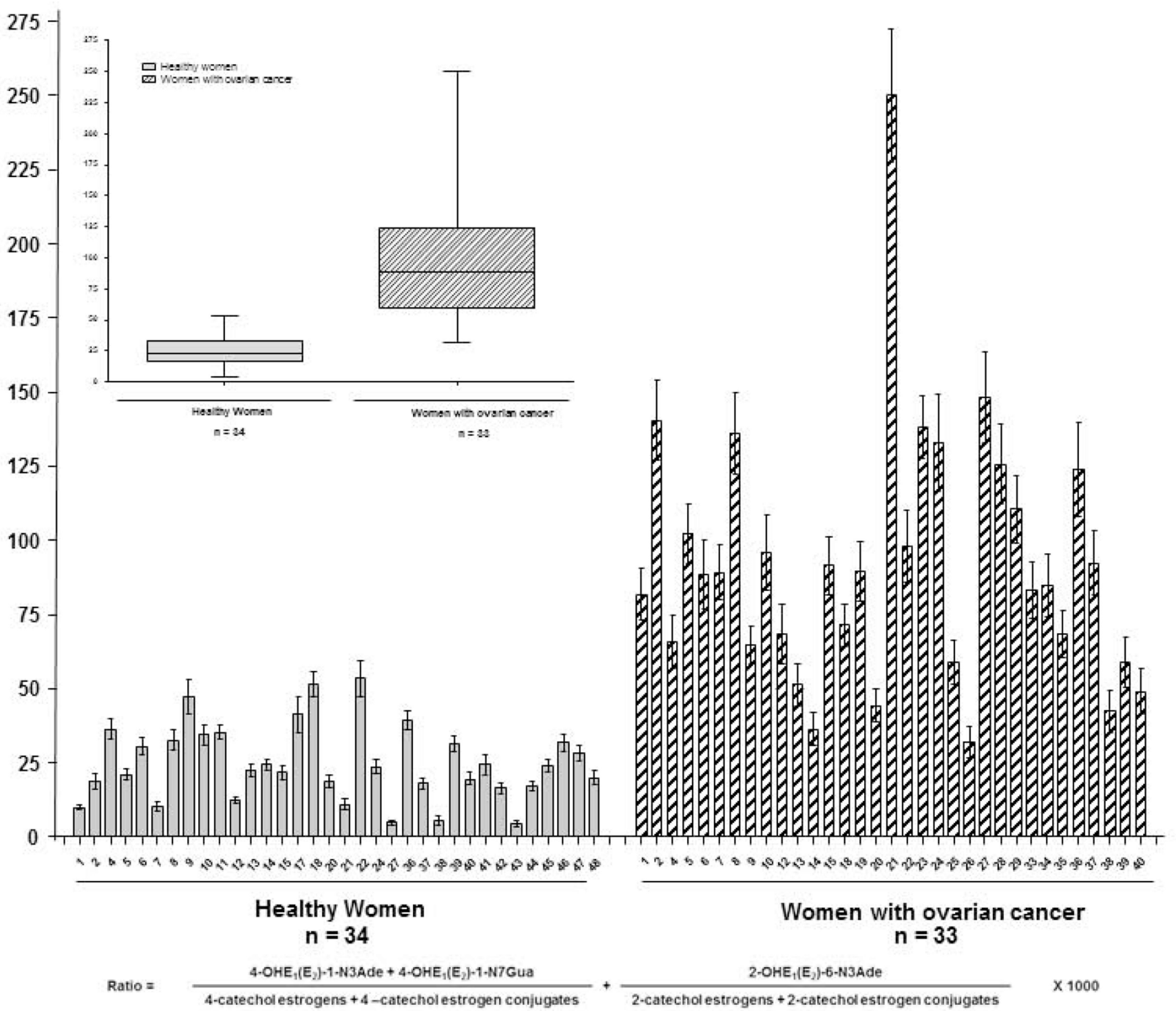

Figure 2.

Ratio of urinary depurinating estrogen-DNA adducts to estrogen metabolites and conjugates for women diagnosed with ovarian cancer (cases) or not diagnosed with cancer (controls). The ratio is defined in the Materials and Methods Section. The dotted line representing a ratio of 43 is the cross-over point for sensitivity and specificity of the ratio (see Fig. 3). Insert: Ratios presented as median values and ranges (min to max). The diamonds represent the mean values. 


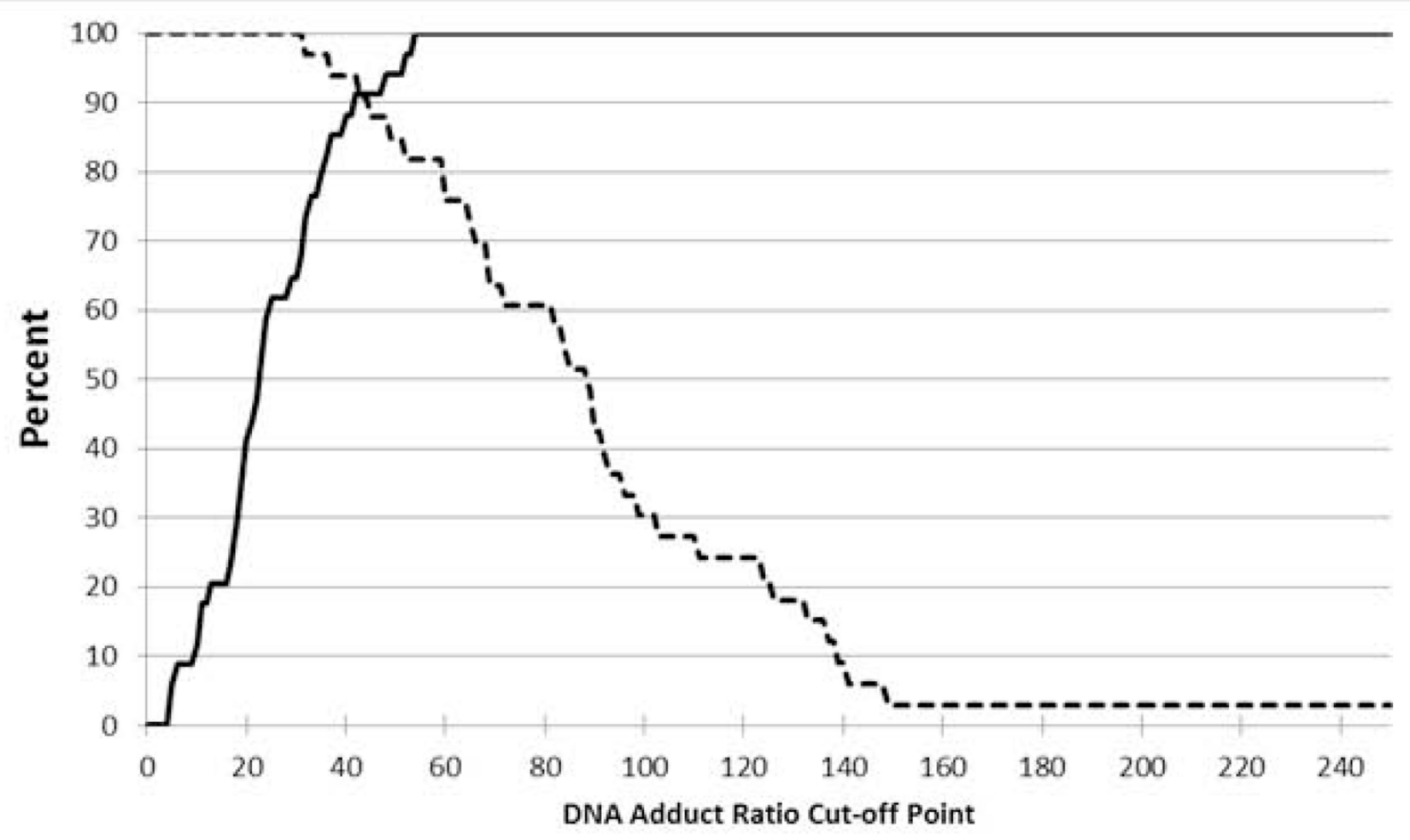

--- Sensitivity $\longrightarrow$ Specificity

Figure 3.

Sensitivity and specificity at cut-points from 0 to 350 of the DNA adduct ratio in 33 cases of ovarian cancer and 34 non-cancer controls; sensitivity equals specificity at an adduct ratio cut-off value of 43 . 


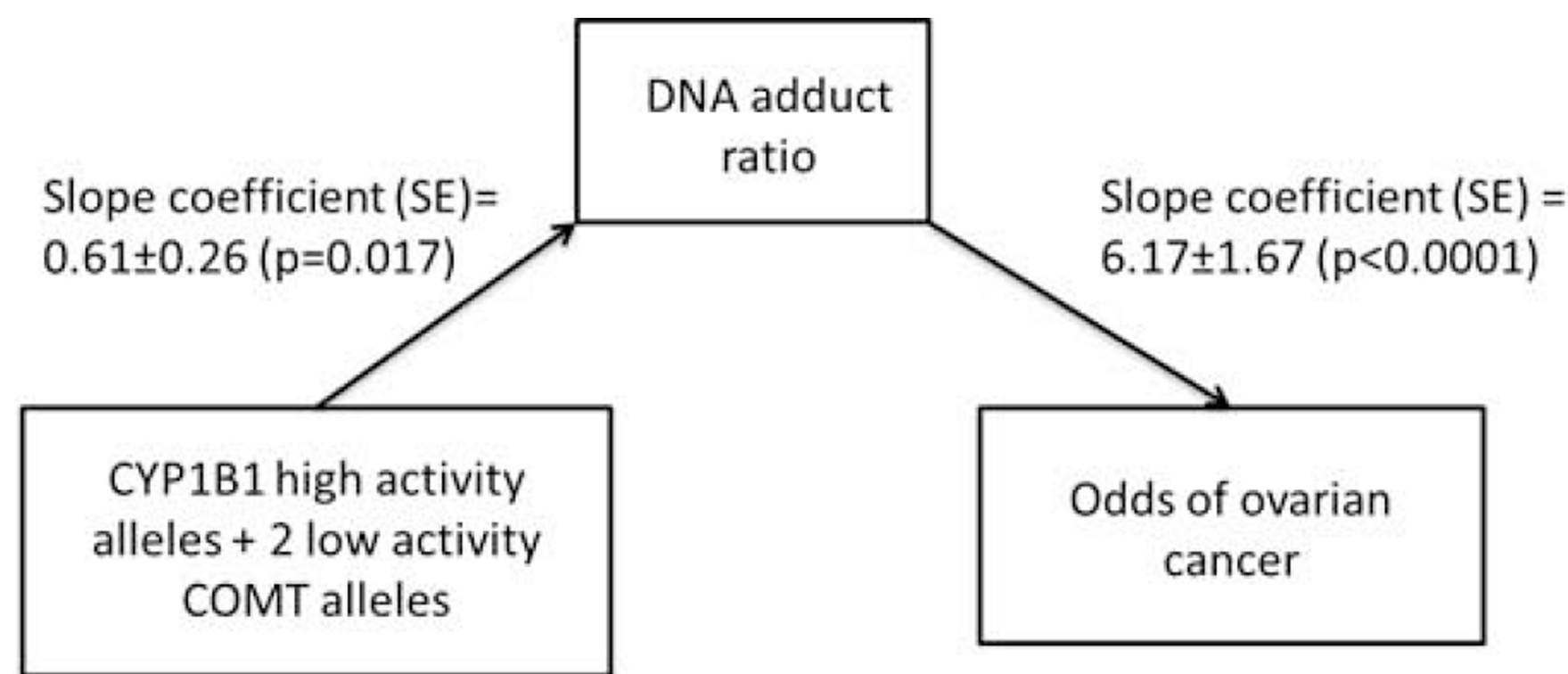

Figure 4.

Maximum likelihood path analysis of having polymorphic alleles in CYP1B1 and COMT, the adduct ratio, and having ovarian cancer in 67 women ( 33 cases and 34 controls). The slope coefficients represent the effect sizes in sequential regression analyses. The path from high-risk genotypes shows a significant increase in the DNA adduct ratio. The second path coefficient indicates a significant increase in the risk of ovarian cancer. 
Table 1

Demographic characteristics and distribution of ovarian cancer risk factors in 67 study participants with complete information and tests for significant differences between cases of ovarian cancer and controls.

\begin{tabular}{|c|c|c|c|}
\hline Sample characteristic & $\begin{array}{c}\text { Entire sample }(n=67) \\
N(\%)\end{array}$ & $\begin{array}{c}\text { Controls }(n=34) \\
N(\%)\end{array}$ & $\begin{array}{c}\text { Ovarian Cancer }(\mathbf{n}=33) \\
\mathbf{N}(\%)\end{array}$ \\
\hline \multicolumn{4}{|l|}{ Race } \\
\hline White & $62(92.5)$ & $33(97.1)$ & $29(87.9)$ \\
\hline African American & $5(7.5)$ & $1(2.9)$ & $4(12.1)$ \\
\hline \multicolumn{4}{|l|}{ Education $c$} \\
\hline$<=$ High school graduate & $33(49.3)$ & $11(32.3)$ & $22(66.7)$ \\
\hline > High school graduate & $34(50.7)$ & $23(67.7)$ & $11(33.3)$ \\
\hline \multicolumn{4}{|l|}{ Marital status } \\
\hline Married & $47(70.1)$ & $26(76.5)$ & $21(63.6)$ \\
\hline Not married & $20(29.9)$ & $8(23.5)$ & $12(36.4)$ \\
\hline \multicolumn{4}{|l|}{ Post-menopausal } \\
\hline No & $3(4.5)$ & $3(8.8)$ & 0 \\
\hline Yes & $64(95.5)$ & $31(91.2)$ & $33(100)$ \\
\hline \multicolumn{4}{|l|}{ Exercise frequency $b$} \\
\hline$>2$ days/ week & $20(30.3)$ & $14(42.4)$ & $6(18.2)$ \\
\hline$<1-2$ days/week & $46(69.7)$ & $19(57.6)$ & $27(81.8)$ \\
\hline \multicolumn{4}{|l|}{ HRT } \\
\hline No & $56(83.6)$ & $28(82.3)$ & $28(84.8)$ \\
\hline Yes & $11(16.4)$ & $6(17.7)$ & $5(15.2)$ \\
\hline \multicolumn{4}{|l|}{ Oral contraceptive use $b$} \\
\hline No & $13(19.4)$ & $3(8.8)$ & $10(30.3)$ \\
\hline Yes & $54(80.6)$ & $31(91.2)$ & $23(69.7)$ \\
\hline \multicolumn{4}{|l|}{ Parity } \\
\hline No children & $13(19.4)$ & $6(17.7)$ & $7(21.2)$ \\
\hline At least one child & $54(80.6)$ & $28(82.3)$ & $26(78.8)$ \\
\hline \multicolumn{4}{|l|}{ Ever smoke cigarettes $a$} \\
\hline No & $28(41.8)$ & $18(52.9)$ & $10(30.3)$ \\
\hline Yes & $39(58.2)$ & $16(47.1)$ & $23(69.7)$ \\
\hline \multicolumn{4}{|l|}{ Current drinker $c$} \\
\hline Yes & $50(74.6)$ & $30(88.2)$ & $20(60.6)$ \\
\hline No & $17(25.4)$ & $4(11.8)$ & $13(39.4)$ \\
\hline \multicolumn{4}{|l|}{ Relative with ovarian cancer } \\
\hline No & $64(95.5)$ & $34(100.0)$ & $30(90.9)$ \\
\hline
\end{tabular}




\begin{tabular}{|c|c|c|c|}
\hline Sample characteristic & $\begin{array}{l}\text { Entire sample }(n=67) \\
N(\%)\end{array}$ & $\begin{array}{c}\text { Controls }(\mathbf{n}=\mathbf{3 4}) \\
\mathbf{N}(\%)\end{array}$ & $\begin{array}{c}\text { Ovarian Cancer }(\mathrm{n}=\mathbf{3 3}) \\
\mathbf{N}(\%)\end{array}$ \\
\hline \multirow[t]{2}{*}{ Yes } & $3(4.5)$ & 0 & $3(9.1)$ \\
\hline & Mean (SD) & Mean (SD) & Mean (SD) \\
\hline Age & $58.3(7.01)$ & $58.4(7.24)$ & $58.1(6.87)$ \\
\hline Age of menarche & $12.9(1.79)$ & $12.8(1.77)$ & $12.9(1.84)$ \\
\hline Age at first baby ${ }^{*} c$ & $24.4(5.75)$ & $26.2(5.29)$ & $22.4(5.67)$ \\
\hline Age at last baby $* a$ & $28.7(5.69)$ & $30.1(5.51)$ & $27.3(5.63)$ \\
\hline Years of oral contraceptives $b$ & $5.91(6.87)$ & $7.56(7.53)$ & $4.21(5.74)$ \\
\hline Age at last menstrual period $a$ & $47.1(7.75)$ & $49.2(6.28)$ & $45.3(8.58)$ \\
\hline BMI & $28.8(5.57)$ & $28.3(4.46)$ & $29.3(6.56)$ \\
\hline Years of cigarette smoking * & $17.4(11.0)$ & $16.0(9.73)$ & $18.3(12.0)$ \\
\hline DNA adduct ratio $d$ & $57.5(45.9)$ & $24.7(12.7)$ & $91.4(43.1)$ \\
\hline \multicolumn{4}{|l|}{$a_{\mathrm{p}<0.10}$} \\
\hline \multicolumn{4}{|l|}{$b_{\mathrm{p}<0.05}$} \\
\hline \multicolumn{4}{|l|}{$c_{\mathrm{p}<0.01}$} \\
\hline \multicolumn{4}{|l|}{$d_{\mathrm{p}<0.0001}$} \\
\hline
\end{tabular}


Table 2

A. Mean adduct levels and prevalence of ovarian cancer cases by genotypes of CYP1B1 and COMT in 66 study participants

\begin{tabular}{lccc} 
Genotype frequencies & $\mathbf{n}$ & $\begin{array}{c}\text { DNA adduct ratio } \\
(\mathbf{M} \pm \text { SD) }\end{array}$ & $\begin{array}{c}\text { Ovarian cancer } \\
\text { Number (\%) }\end{array}$ \\
\hline CYP1B1 & 21 & $47.5 \pm 32.5$ & $9(27.3)$ \\
CC & 29 & $54.7 \pm 39.4$ & $14(42.4)$ \\
CG & 16 & $78.1 \pm 65.4$ & $10(30.3)$ \\
GG & & & $7(21.9)$ \\
COMT & 11 & $61.0 \pm 34.2$ & $14(43.7)$ \\
GG & 37 & $47.7 \pm 38.4$ & $11(34.4)$ \\
GA & 18 & $75.5 \pm 61.7$ & Ovarian cancer \\
AA & & DNA adduct ratio & \\
\hline & $\mathbf{M} \pm$ SD) & \\
Genotype frequencies & $\mathbf{n}$ & & $9(27.3)$ \\
\hline CYP1B1 & & $47.5 \pm 32.5$ & $24(72.7)$ \\
CC & 21 & $63.0 \pm 50.7$ & $7(21.9)$ \\
CG/GG & 45 & & $25(78.1)$ \\
COMT & & $61.0 \pm 34.2$ & \\
GG & 11 & $56.8 \pm 48.5$ & \\
GA/AA & 55 & & \\
\hline
\end{tabular}

B. Descriptions and t-tests for association between the DNA adduct ratio and having one or two high activity CYP1B1 alleles in the presence of being homozygous for the mutant allele resulting in low COMT activity

\begin{tabular}{|c|c|c|c|c|}
\hline Risk combination & $\mathbf{n}$ & $\begin{array}{c}\text { Mean adduct ratio } \\
\text { (SD) }\end{array}$ & $\begin{array}{c}\text { T-test } \\
\text { (p-value) }\end{array}$ & $\begin{array}{c}\text { Ovarian Cancer } \\
\text { OR }(95 \% \text { CI })\end{array}$ \\
\hline \multicolumn{5}{|c|}{$\begin{array}{l}\text { CYP1B1 GC or GG + COMT } \\
\text { AA }\end{array}$} \\
\hline No & 52 & $49.7(36.8)$ & -2.43 & Reference \\
\hline Yes & 13 & $91.4(64.9)$ & $(0.018)$ & $2.84(0.77-10.4)$ \\
\hline \multicolumn{5}{|c|}{ CYP1B1 GG + COMT AA } \\
\hline No & 59 & $51.9(37.6)$ & -2.43 & Reference \\
\hline Yes & 6 & 118.5 (79.5) & $(0.018)$ & $5.93(0.65-53.9)$ \\
\hline
\end{tabular}

